\title{
Paulo Assunção
}

\section{O “TERREMOTO” NA EDUCAÇÃO PROVOCADO PELO MARQUÊS DE POMBAL}

\section{RESUMO}

Este artigo tem como objetivo apresentar as transformações decorrentes das intervenções políticas e administrativas feitas pelo Marquês de Pombal, enquanto Primeiro-Ministro. É destacado o contexto pós terremoto de 1755, dando ênfase para as transformações urbanas em recurso e a remodelação do sistema de educação de Portugal e de todo o seu vasto império colonial. A expulsão dos jesuítas e a penetração das ideias iluministas deram ensejo a transformações no âmbito do ensino. A criação do Colégio dos Nobres e principalmente as reformas da Universidade de Coimbra fizeram que modelos pedagógicos fossem revistos. Tais modificações sinalizam para um novo momento da história de Portugal que foi possível graças ao "terremoto" provocado pelo Marquês de Pombal.

Palavras-chave: Educação, Pombal, Lisboa, Iluminismo, Jesuítas 


\section{THE “EARTHQUAKE” IN THE EDUCATION CAUSED BY THE MARQUIS OF POMBAL}

\section{ABSTRACT}

This article aims to present the changes resulting from the political and administrative interventions made by the Marquis of Pombal as Prime Minister. It highlighted the post-earthquake context of 1755 , with emphasis on the urban transformations in resource and remodeling the education system in Portugal and in its vast colonial empire. The expulsion of the Jesuits and the penetration of the Enlightenment ideas supported changes in teaching. The creation of the College of Nobles and especially the reform of the University of Coimbra led to revisions in the pedagogical models. Such changes pointed to a new moment in the history of Portugal which was possible thanks to the "earthquake " caused by the Marquis of Pombal.

Keywords: Education, Pombal, Lisbon, Enlightenment, Jesuits

\section{EL“TERREMOTO” EN LA EDUCACIÓN CAUSADO POR EL MARQUÉS DE POMBAL}

\section{RESUMEN}

Este artículo tiene como objetivo presentar las modificaciones resultantes de las intervenciones políticas y administrativas realizadas por el Marqués de Pombal como Primer Ministro. Se puso de relieve el contexto posterior al terremoto de 1755, con énfasis en las transformaciones urbanas en recurso y la remodelación del sistema de educación Portugal y su vasto imperio colonial. La expulsión de los jesuitas y la penetración de las ideas ilustradas dieron lugar a cambios en la enseñanza. La creación del Colegio de Nobles y en especial las reformas de la Universidad de Coimbra hicieron que se revisaron los modelos pedagógicos. Tales cambios indican un nuevo momento en la historia de Portugal que fue posible gracias al "terremoto" causado por el Marqués de Pombal.

Palabras clave: Educación, Pombal, Lisboa, Ilustración, Jesuitas.

\section{LE“ TREMBLEMENT”DANS L'ÉDUCATION PROVOQUÉ POUR LE MARQUIS DE POMBAL}

\section{RÉSUMÉ}

Cet article a l'objectif de présenter les transformations résultantes des interventions politiques et administratives réalisées pour le Marquis de Pombal,quand il était premier ministre. Nous détachons le contexte après le tremblement de 1755,en détachant les transformations urbaines et un noveau modèle du système éducatif portugais et de tout le vaste empire colonial. L’expulsion des jésuites et la pénétration des idées des lumières ont donné l’opportunité de transformations dans les sphères d’enseignement. La création du Collége des Nobles et principalement les réformes de l'Université de Coimbra ont fait que des modèles pédagogiques fussent révisés.Telles modifications indiquent un noveau moment de l'histoire du Portugal qui a été possible grâce au "tremblement"provoqué pour Marquis de Pombal.

Mots-clés : Éducation, Pombal, Lisbonne, Lumières, Jésuites. 
NO ALVORECER DO DIA primeiro de novembro de 1755 a terra tremeu em Lisboa e nas áreas adjacentes. $\mathrm{O}$ abalo foi seguido de incêndio e de maremotos, fazendo que o caos se instaurasse na cidade. O número de mortos foi elevado, como também os danos materiais causados pela força da natureza. Os sobreviventes atônitos não encontravam explicação adequada para o acontecido. A desgraça que se abatera sobre todos fizera que a população apelasse para a devoção religiosa. ${ }^{1}$ Sebastião José de Carvalho e Melo, ciente do seu papel, fez um pronunciamento sobre o que seria possível de alcançar com a desgraça causada pelo terremoto. Velhas estruturas sucumbiam, cedendo espaço para que um novo edifício fosse erguido. Portugal precisava reconstruir não apenas a cidade de Lisboa, mas sim toda uma sociedade. ${ }^{2}$

As equipes que se formaram, logo após a tragédia, tiveram a missão de desobstruir a cidade. Tarefa difícil e demorada. Os escombros impediam que os trabalhos se realizassem na rapidez desejável, enquanto outras medidas eram tomadas. O desentulhamento foi lento, revelando a dificuldade de se recompor a cidade.

Contudo, a sociedade portuguesa sofreria um novo abalo tão forte quanto o terremoto. Em setembro de 1758, D. José I, retornando ao palácio, após uma visita noturna à marquesa de $\mathrm{D}$. Teresa de Távora $\mathrm{e}$ Lorena (1723-?), esposa de D. Luís Bernardo de Távora (1723-1759), foi emboscado por desconhecidos que o feriram. ${ }^{3} \mathrm{O}$ caso ficou envolvido em mistério e foi devidamente explorado por Sebastião José de Carvalho e Melo, que empreendeu diligências secretas para descobrir os executores de tal delito. ${ }^{4}$ Em dezembro do mesmo ano, numa operação policial rápida, alguns políticos importantes, dentre eles líderes aristocratas como o conde de Atougia e o duque de Aveiro, bem como componentes da família dos Távora foram presos, demonstrando uma forte conotação política na perseguição, tendo como objetivo neutralizar a ação da nobreza. As averiguações apontaram também para o envolvimento de alguns jesuítas que teriam atuado como cúmplices no atentado, o famoso Padre Gabriel Malagrida e os padres João de Matos e João Alexandre. ${ }^{5}$ Este episódio completava uma série de entraves com a Companhia de Jesus, justificando o alvará real de 1759, que ordenava o afastamento daqueles que serviam na corte como preceptores ou confessores da família real e a prisão e a expulsão dos jesuítas. ${ }^{6}$

$\mathrm{O}$ ato de expulsão era realizado com o fim de preservar a autoridade real e a soberania do Estado lusitano, colaborando também para a harmonia da sociedade ameaçada pelos religiosos. $\mathrm{O}$ argumento utilizado era que a Igreja e especialmente a Companhia de Jesus não estavam submetidas aos reis portugueses, acabando por criar o que ficou conhecido como um Estado dentro do Estado, duas monarquias, uma temporal e outra espiritual. Esta atitude, antes de ser um ato monárquico, era uma ação em prol da segurança da coletividade, pois a punição dada aos nefastos religiosos visava a "conservar a tranqüilidade, e interesses dos fiéis vassalos". A expulsão assumia, portanto, ares de proteção e defesa dos súditos à mercê de religiosos que não mediam esforços para conseguir os seus intentos. Expulsão que causaria uma série de transformações no reino e no império lusitano. A dimensão dada ao episódio e o tom dramático em parte contribuíram para abrir campo para as mudanças, gerando transformações mais profundas.

Sebastião José de Carvalho e Melo no seu pronunciamento sobre as vantagens que o reino poderia alcançar da desgraça causada pelo terremoto lembrava que, para restabelecer um Estado, era necessário que um Estado fosse em parte aniquilado. $\mathrm{O}$ tremor, enquanto fenômeno da natureza, permitia destruir alguns sistemas que não eram condizentes com a nova realidade $\mathrm{e}$ os novos interesses. ${ }^{7}$

Portugal sofreu uma reformulação institucional, estruturada por Sebastião José de Carvalho que, ao assumir suas funções de Primeiro-Ministro, procurou fortificar o Estado, impedindo o comportamento desregrado da elite portuguesa que gozava de prerrogativas estimuladoras de práticas irregulares. A Igreja e a nobreza viviam com grandes recursos enquanto a população caminhava na pobreza. O Primeiro-Ministro desejava aprofundar a centralização do poder monárquico frente à Igreja e à nobreza e sanear as finanças do Estado. Para tanto, procurou atuar por meio de leis que clarificassem o papel das instituições, bem como as relações existentes entre elas. Como bem salientou Lilia 
Schwarcz, a assunção de Sebastião José de Carvalho e Melo não representava, "entretanto, apenas a conquista pessoal de um político de carreira fulminante. Era também a vitória de um certo ideal administrativo e de um grupo que soube apresentar, no momento certo, uma série de saídas emergenciais". ${ }^{8}$

A centralização de poder almejava reorganizar o império português, extremamente debilitado em sua balança comercial, especialmente com a Inglaterra, pelos acordos econômicos celebrados entre os dois países, especialmente o Tratado de Methuen. O saneamento das contas do Estado passava pela revisão das relações de dependência e pela sangria de recursos que debilitaram as finanças. A criação da Companhia do Grão-Pará e Maranhão e da Companhia de Pernambuco e Paraíba, instituídas em 1755 e 1759, respectivamente, tinha como objetivo acelerar o desenvolvimento econômico daquelas regiões coloniais, favorecendo a exploração natural e o cultivo do açúcar e do fumo. Fernando Novais destacou que a política ilustrada pombalina era essencialmente reformista e visava a solucionar a crise do sistema colonial, afetando por decorrência as relações do Antigo Regime, pois, conforme observa o autor: "Absolutismo, sociedade estamental, capitalismo comercial, política mercantilista, expansão ultramarina e colonial são, portanto, parte de um todo, interagem reversivamente neste complexo a que se poderia chamar, mantendo um termo da tradição, Antigo Regime" ${ }^{\text {". Neste }}$ universo, o poderio jesuítico tornara-se, com o decorrer do tempo, um elemento nocivo à saúde do Estado em todas as suas esferas, reduzindo a ação do rei e abalando principalmente os recursos do Erário Real. O problema não era apenas a ação da Companhia, como observou Francisco Falcon:

O processo de debilitação do poder do Estado, com suas inevitáveis seqüelas, traduzidas sob a forma de inércia, ineficiência e aumento da corrupção no aparelho burocrático, abriu caminho aos descontentamentos e às pretensões daquelas camadas ou grupos da burguesia mais diretamente prejudicados, ou mais dispostos a contestar o crescimento relativo da aristocracia.
Sebastião José de Carvalho Melo identificou o enfraquecimento do poder real, entendendo ser preciso restabelecer a ordem econômica do Estado português. ${ }^{10}$ Paulatinamente, reorganizava-se o Estado adequando a justiça e o comércio à nova conjuntura, bem como o exército. ${ }^{11}$

No decorrer da segunda metade do século, Portugal passaria por uma intensa transformação mental e social, impulsionada por forças externas e internas, sendo o terremoto apenas uma das rupturas do processo histórico português. ${ }^{12}$ A Europa vivia um momento de efervescência ideológica movida pela ideia da força da razão. O homem pensando por si mesmo procurava atingir pela reflexão a solução de seus problemas. A possibilidade de ele intervir nos seus desígnios ficava evidente, bastava ao ser humano compreender a razão universal. A influência de ideias científicas e filosóficas já era intensa, fruto de um movimento de longa duração no decorrer da primeira metade do século. ${ }^{13}$

Nas cortes europeias a afirmação do poder temporal sobre o poder espiritual marcava uma nova relação do Estado com a Igreja. O pensamento iluminista foi profícuo na discussão da liberdade e autonomia do Estado em relação à Igreja. ${ }^{14}$ As reflexões tentaram harmonizar a ciência e a fé, o racional e o experimental, visando a conciliar o tradicional com a inovação, deixando clara a necessidade de sistematização dos novos valores e conhecimentos promovidos pelo avanço do pensamento científico. Tarefa difícil de ser conduzida, tendo em vista as raízes profundas do pensamento conservador na massa da população. Procurava-se revisar os conhecimentos a fim de incorporar as novas ideias apresentadas pela Ilustração a uma minoria. ${ }^{15}$

O debate sobre a revisão dos conhecimentos passou pelo questionamento da educação e dos sistemas pedagógicos. Uma sociedade mais justa só seria possível se houvesse uma mudança de hábitos e costumes, rompendo as barreiras do preconceito. A emergência de um Estado progressista pressupunha uma educação de base científica, que respeitasse o bem comum, a qual deveria nortear as Escolas e Academias, até então influenciadas de maneira intensa pelos jesuítas. A secularização da educação passou a ser uma bandeira propagada pelo pensamento iluminista que visava a garantir a forma- 
ção de um ser humano na sua integralidade.

Questionava-se a tradição e defendia-se uma postura mais crítica em relação à mesma. Segundo Nicola Abbagnano, o Iluminismo via a tradição com uma "força hostil" que mantinha viva as crenças e preconceitos que precisava ser destruídos. Permeia as ideias do período a "recusa em aceitar a autoridade da tradição e reconhecer nela qualquer valor independente da razão". Para este autor o Iluminismo não era apenas o uso crítico da razão, mas, sobretudo o compromisso do homem em "utilizar a razão e os resultados que ela pode obter nos vários campos de pesquisa para melhorar a vida intelectual e social" da humanidade. ${ }^{16}$

A publicação da obra de Luís António Verney (1713-1792), intitulada Verdadeiro Método de Estudar, apesar de confiscada pela Inquisição portuguesa, entrou no reino lusitano e acabou por influenciar no direcionamento de algumas ações empreendias por Sebastião José de Carvalho e Melo. Verney nascera em Lisboa onde viveu até a idade de vinte e três anos. Em seguida partiu para Roma a fim de dar continuidade aos estudos de Teologia e Jurisprudência e, ao retornar a Portugal, trazia na bagagem uma nova visão. Nesta obra, Verney aproveitava para criticar de forma veemente o sistema pedagógico dos inacianos, tanto no que dizia respeito ao seu conteúdo como ao seu método. ${ }^{17}$ Questionava o ensino português e defendia que era necessária a reforma do modelo vigente. As críticas de Luís António Verney baseavam-se no ideário iluminista. Porém, a sua proposta não entrava em confronto com a revelação e a graça divina, nem procurava sobrepor a razão a estas. Atribuía o atraso e a decadência de Portugal ao enclausuramento em que vivia o país. No seu entender, era necessário abrir espaço para novas ideias, conforme outras monarquias já o faziam. Enfim, libertar Portugal do claustro. ${ }^{18}$

Esta ideia foi compartilhada por outros pensadores. Antonio Nunes Ribeiro Sanches (1699-1783), cristão-novo, foi outro expoente da ilustração em Portugal, que exerceu influência na política pombalina. O ponto comum entre ele e Verney residia na identificação da necessidade de superar o atraso cultural do reino. ${ }^{19}$

Sebastião José de Carvalho e Melo ao assumir o cargo de Primeiro-Ministro do governo de D. José I construiria um conjunto de políticas que visava a reformar o Estado lusitano, considerando parte das ideias destes pensadores. O seu projeto não se ateve apenas à educação, apesar de esta ser um dos pontos fundamentais da sua política. As ações políticas no sentido da centralização do poder e as ações econômicas de essência mercantilista revelam que Sebastião José de Carvalho e Melo habilmente construiu um aparato institucional e administrativo para garantir a sustentação e o funcionamento do Estado português..$^{20} \mathrm{~A}$ centralização feita por Sebastião José de Carvalho e Melo foi acompanhada de práticas mercantilistas que controlaram e restringiram as atividades comercias para garantir os interesses de determinados grupos. Era necessário fortalecer as exportações portuguesas a fim de que a classe mercantil florescesse e conseguisse dinamizar a economia, uma vez que o terremoto havia gerado grandes problemas.

Os cofres do Erário público estavam dilapidados, os setores que compunham a sociedade viviam em conflito; além disso, havia o atraso no ensino marcado pelos métodos tradicionais, conforme registrara Luís Antonio Verney. Neste sentido, Pombal entendia que o Estado deveria ser o responsável pela formação dos jovens, renovando a mentalidade portuguesa, em especial da elite. ${ }^{21} \mathrm{~A}$ educação até então notoriamente influenciada pela religião passaria pelo processo de secularização. Podemos dizer que havia necessidade de uma aceleração histórica. As reformas desenvolvidas por Sebastião José de Carvalho Melo foram movidas pela modernização que se contrapunha à ideia de atraso e decadência da sociedade e da cultura portuguesa; a ideia de um novo espírito científico exigia novas maneiras de pensar, inclusive do próprio poder do Estado. Em parte, o atraso de Portugal e das colônias se devia à forte dominação da Igreja e em especial dos jesuítas, responsáveis pela consolidação de uma ordem imutável. O novo momento impulsionado por Sebastião José de Carvalho Melo apresentava uma modernização que rompia o equilíbrio de um universo governado pelas leis divinas. A expulsão dos jesuítas, a condenação do Pe. Malagrida e a alteração do modelo de educação impuseram uma transformação abrupta à sociedade lusitana, como aquelas que ocorreram no âmbito econômico. ${ }^{22} \mathrm{~A}$ assimilação de um modelo edu- 
cacional, fundada no uso da teoria da razão, só teria seus resultados alguns anos mais tarde.

A ruptura impunha uma mudança de princípio, um novo conhecimento, em especial aquele que fosse útil à sociedade, devendo partir da própria monarquia. A educação dos herdeiros da coroa deveria compreender uma formação intelectual mais sólida que respaldasse a arte de governar, desde que seguisse as diretrizes definidas pelo Primeiro-Ministro; caso contrário, estava fadado à perseguição.

A educação ministrada pelos jesuítas marcou o início da História da Educação no Brasil. No decorrer da sua atuação, os jesuítas foram responsáveis pela sistematização e organização educacional, estabelecendo colégios que visavam a dar uma formação básica para a população, fazendo que a cultura europeia cristã marcasse sua presença nas terras tropicais. A conquista espiritual implicou a imposição de uma educação religiosa, sendo as escolas de ler e escrever o primeiro meio utilizado para a divulgação. $\mathrm{O}$ estabelecimento de colégios destinados aos filhos dos colonos brancos foi a etapa seguinte, a ser consolidada. Os colégios permitiam que os filhos de uma elite colonial conseguissem realizar seus estudos para, em seguida, aqueles que possuíssem recursos, complementarem a sua formação em Portugal ou na Europa.

Por ocasião da expulsão, a Companhia de Jesus contava com mais de vinte colégios e de trinta e seis missões espalhados pelo território. A expulsão dos jesuítas gerou um caos no cenário educacional. $\mathrm{O}$ impacto não foi sentido somente no ensino das primeiras letras, pois os cursos de Letras e Filosofia, mantidos pelos religiosos, também sofreram o impacto.

Independente de o método jesuítico ser considerado especulativo e inadequado aos interesses da metrópole, ele atendia ao contexto colonial em face da ausência de uma política educacional do reino lusitano. Neste sentido, podemos observar que o projeto de Sebastião José de Carvalho e Melo atendia na primeira fase aos interesses da elite, o que implica afirmar que almejava consolidar um projeto de educação sólido em longo prazo para os demais habitantes da colônia. $\mathrm{O}$ desmantelamento do ensino jesuítico foi mais grave em razão da carência de professores e de recursos para implementação de um novo modelo educacional. ${ }^{23}$ Sebastião José de Carvalho e Melo, ao romper com os equívocos anteriores, teve contra si a ausência de recursos para efetivar o novo projeto e a resistência da elite colonial em abraçar as mudanças.

A reformulação propunha situar o ensino sob o controle do Estado, uma vez que os colégios jesuíticos tinham um domínio acentuado na formação dos jovens das classes dominantes do reino. Nessa reformulação, a língua portuguesa era imposta como língua oficial e exclusiva. Uma política pública de ensino poria fim aos desvios, unindo todos sob o controle do Estado e de uma só língua e, neste sentido, a proposta de reforma da educação não era meramente pedagógica, mas principalmente política. O ensino tinha um propósito essencialmente utilitário, como observou Kenneth Maxwell: "criar um corpo de funcionários educados segundo as idéias iluministas, dispostos a reformar a burocracia do Estado e a hierarquia da Igreja". ${ }^{24}$ Desta maneira, seria possível a criação de um grupo de funcionários, burocratas e clérigos capazes de defender as ideias sugeridas pela reforma.

Deve-se ressaltar que as ações do governo de D. José I, no que tange à colônia, revelaram também outras preocupações. A reduzida população que habitava a vasta América Portuguesa era um fato preocupante, na medida em que permitia vazios demográficos em determinadas regiões, principalmente aquelas de fronteira como a Amazônica, situação comprometedora para a soberania lusitana na região. Apesar de fomentar a imigração do Reino e das ilhas atlânticas para a colônia, o resultado foi aquém do necessário, em razão de sua amplitude territorial, um desafio que exigia um número de imigrantes sempre maior. Concomitantemente, procurando abolir as diferenças existentes entre portugueses e índios, estimulou-se a miscigenação e o reconhecimento dos filhos oriundos do casamento entre homens brancos e homens indígenas que, doravante, teriam os mesmos direitos que os naturais do Reino. A questão da demografia não foi um problema apenas para a soberania de Portugal. A dispersão da população por um território tão extenso impediu que uma ação mais eficaz no âmbito da educação fosse atingida. Por conseguinte, o governo monárquico adotou 
uma política em que as ordens religiosas, além das suas preocupações espirituais, deveriam auxiliar a coroa na formação de povoações que fortalecessem a ocupação portuguesa. O ensino obrigatório da língua portuguesa fazia parte do processo de transformação dos indígenas em súditos do monarca.

A recusa em conceder poder temporal às missões e povoações, por parte dos jesuítas, foi um dos motivos do estremecimento das relações entre eles e a coroa e a consequente expulsão. Uma série de entraves, tanto na definição do Tratado de Limites e na região amazônica, demonstrou os obstáculos que a coroa teria no efetivo controle do poder temporal.

Em 13 de janeiro de 1750, era celebrado o Tratado de Limites dando a posse da Colônia do Santíssimo Sacramento à Espanha, enquanto Portugal ficava com os Sete Povos das Missões ${ }^{25}$ e reconhecia o domínio português na região do Amazonas, Maranhão e Mato Grosso, assim como a posse definitiva das Filipinas, pelos espanhóis. Tal divisão, feita à revelia dos interesses e desejos dos jesuítas, afetava as aldeias dos índios missioneiros que deveriam deslocar-se para as terras demarcadas, seguindo o acordo celebrado entre as duas coroas. A partir de 1751, são realizados entre as coroas ibéricas acordos secretos, estabelecendo adoção de procedimentos, caso houvesse resistência dos índios que habitavam a região, negando-se a cumprir o Tratado de Limites. ${ }^{26}$ D. José I determinou aos seus agentes que, na execução da troca de territórios, fosse garantida a simultaneidade da passagem de terras, e que a responsabilidade da desocupação era das duas coroas. Os jesuítas, por suas vez, assediaram os reis de Portugal e da Espanha para que o tratado não fosse executado, chamando a atenção para o fato de que as reduções correriam grande risco, e a paz espiritual e temporal estavam ameaçadas, argumentos que não foram considerados pelos monarcas.

As novas resoluções geraram a resistência e o enfrentamento dos guaranis (guerras guaraníticas 17541756), ${ }^{27}$ sendo os jesuítas acusados de repelir o Tratado, estimular a resistência, instigando os índios a se rebelarem contra as decisões do poder real português e espanhol. As negociações para demarcar a fronteira na região da bacia amazônica não foram menos turbulentas do que aquelas ocorridas na região platina. Os pontos principais dos ataques atinham-se aos abusos dos religiosos da Companhia de Jesus nos domínios da América Portuguesa e Espanhola quanto à usurpação da liberdade dos índios, não respeitando às resoluções dos reis e às leis que tratavam do assunto; ${ }^{28}$ quanto à propriedade dos bens nas terras das suas habitações e à perpétua cura das paróquias, ignorando o preceito de que os religiosos só seriam párocos, enquanto não houvesse clérigos; quanto aos governos temporais das aldeias, interferindo nos governos seculares e ao comércio terrestre e marítimo, realizando negociações que não eram "decentes aos Clérigos". ${ }^{29}$ Este último ponto, sem dúvida, chama a atenção dos acusadores da Companhia que buscavam, por meio dos textos legais, demonstrar as práticas inconvenientes dos religiosos, como "o mandar buscar drogas aos Sertões pelos Índios, para depois as mandarem vender; o mandarem salgar carnes, e peixes para o mesmo fim; o mandarem salgar, e acumular couros para também venderem". Segundo os opositores, tais transações não eram vendas de coisas supérfluas, nem tampouco de coisas necessárias, mas sim práticas de negociações e tratos mercantis, ${ }^{30}$ que eram proibidos pelas leis do reino. ${ }^{31}$ Conforme observou Joaquim Veríssimo Serrão, D. José I estranhava que, passados tantos anos após a colonização do Maranhão e do Grão-Pará, "se mantivesse instável a situação dos índios, dado o pequeno número das suas povoações e dos que se beneficiavam da doutrina cristẫ. ${ }^{32}$

O problema ganhou contornos mais nítidos após o estabelecimento das Companhias de Comércio e a proibição da remessa direta de mercadorias para o reino, ficando condicionada à entrega das produções nos armazéns para serem transportados pela empresa monopolista. A Companhia de Jesus tomou posição contrária à implementação desta política, ancorando-se no descontentamento entre os comerciantes e armadores desfavorecidos pela medida. A reforma econômica, na realidade, permitiu a reorganização do aparelho administrativo e fiscal e acirrou os ânimos dos colonos e daqueles identificados com os interesses coloniais, ante o conjunto de decisões que visavam a aumentar a receita régia e controlar mais rigidamente a população.

Por outro lado, ante o declínio da exploração aurífera, a coroa procurou estimular a exploração dos 
recursos naturais da colônia (madeiras, cacau, canela etc.) adotou medidas para estimular o desenvolvimento da agricultura comercial e estimulou a criação de gado.

A proposta de Pombal para reerguer Portugal, diante das potências europeias, incluía uma série de transformações inclusive no âmbito da educação, que seria o grande agente transformador. Sebastião José de Carvalho e Melo entendia que os jesuítas estavam preocupados apenas com a formação de religiosos para a própria Companhia de Jesus, enquanto ele propunha organizar a Educação segundo os interesses do Estado, que deveria chamar para si esta responsabilidade. A ideia de uma Educação útil para sociedade era fundamental para a consolidação do próprio Estado.

Se pensarmos a Educação como o um dos elementos capazes de evidenciar o modo como a sociedade se organiza e/ou se desorganiza, notaremos que a monarquia portuguesa passava por um processo de transformação e reorganização da sociedade. Sebastião José de Carvalho Melo era o empreendedor desta reorganização e dos novos valores consolidáveis a longo prazo.

Pelo alvará de 28 de junho de 1759, foi suprimida a escola jesuítica de Portugal e de todas as colônias. Para substituí-los, criou as Aulas Régias de Latim, Grego e Retórica. Conforme a proposta, cada aula régia era autônoma e isolada, com um professor único. Este seria indicado pelo bispo ou teria a sua aquiescência, já que um dos objetivos da educação era a divulgação da doutrina cristã. Os professores detinham o cargo de forma vitalícia, tendo como meta a difusão da língua portuguesa entre os indígenas. Os manuais escolares deveriam ser modernizados a fim de atender as novas exigências.

O tempo indicaria as dificuldades para a implementação de uma rede de ensino na colônia, tanto pelos custos que implicava, como pela inexistência de professores habilitados para pôr em prática o novo modelo. Nas principais capitanias como a da Bahia, Rio de Janeiro, São Paulo e Pernambuco foram instituídas escolas com mestres de ler, escrever e contar, e ainda professores para Gramática, Grego, Retórica e Filosofia. Tendo em vista a falta de professores, os alunos que se destacavam na aprendizagem passavam a ensinar aos seus colegas o conhecimento aprendido. Apesar da cria- ção das diversas cadeiras, o ensino público não obteve sucesso, concorrendo para isto fatores desde a falta de pessoas habilitadas que permitisse ministrar aos jovens os conhecimentos básicos até as remunerações reduzidas oferecidas aos professores, tornando a atividade pouco atrativa, principalmente nas regiões afastadas. A lentidão do processo revela a grande dificuldade para a sua implementação.

Por outro lado, as ações realizadas no reino revelam uma proposta voltada para indústria e para o trabalho capaz de superar os obstáculos enfrentados pela influência da Igreja no Estado, em especial a da Companhia de Jesus.

Em 1761, Pombal fundou em Lisboa o Colégio dos Nobres. ${ }^{33} \mathrm{O}$ seu intento era criar um ensino progressista e científico para atender as novas necessidades do Estado e dos avanços técnicos em marcha, conforme havia proposto Ribeiro Sanches nas suas Cartas sobre a educação da mocidade. Os filhos dos nobres, na faixa etária entre sete e treze anos, recebiam no colégio uma formação diversificada que incluía: retórica, poética, grego, latim, história, inglês, francês, lógica, geografia náutica e arquitetura militar, superando a educação doméstica preponderante entre a elite. Era evidente que a proposta visava à formação moral e intelectual de cidadãos que pudessem atuar em proveito da pátria nas diversas partes do império. Neste sentido, para uma forma de gestão administrativa, era conveniente privilegiar a elite dominante em detrimento dos demais habitantes do império. A formação dos jovens cidadãos visava ao desenvolvimento econômico e à formação de homens para atuarem na vida pública. Esta ideia era uma das ramificações da política implantada por Sebastião José de Carvalho Melo no que dizia respeito à delimitação das categorias nobiliárquicas. Naquele momento, a nobreza lusitana dominava a maior parte dos cargos importantes do Estado, de maneira hereditária, fossem de emolumentos ou de distinção, tais como: presidências de tribunais, comissões diplomáticas, governos das colônias, postos de comando do exército. Contudo, as competências e habilidades nem sempre eram condizentes com o exercício da função.

Em 1771, o Primeiro-Ministro empreende a segunda etapa da reformulação do ensino português, 
criando a Junta de Providência Literária tendo como uma das suas atribuições elaborar novos estatutos para a Universidade de Coimbra. ${ }^{34}$

A 28 de outubro do ano seguinte, os novos estatutos aprovados revelavam o objetivo de adequar os quadros universitários aos avanços do pensamento $\mathrm{e}$ da técnica, afastando da formação o ensino com base escolástica, numa tentativa de aproximar-se da ideologia iluminista, na medida em que se enfatizavam as disciplinas científicas. Aos jesuítas coube a responsabilidade pelo atraso e pelas dificuldades da Universidade de Coimbra e pelo sistema de ensino em vigor. Desta forma, a Universidade de Coimbra passou a receber jovens que obtinham uma formação virtuosa, muitos deles vindos da colônia brasileira. Deve-se ressaltar que, além da necessidade de um quadro de administradores eficazes nas colônias, era fundamental o desenvolvimento de setores econômicos que até então permaneciam inexplorados. Como observa Guilherme Braga da Cruz estas reformas, de inspiração iluminista, fizeram que o Estado assumisse o seu verdadeiro papel no que tange à educação, entendendo que por esta via é que seria possível atingir o ideal de homem livre, racional. ${ }^{35}$ Para Maria Eduarda Cruzeiro, que estudou a reforma pombalina, o novo modelo de ensino era reflexo "de novos modos de legitimação no exercício do poder das classes dominantes, segundo a qual à instituição pedagógica passava a ser pedida uma contribuição própria, mais alargada, para reprodução da estrutura das relações entre as várias forças sociais". ${ }^{36}$

O subsídio literário, criado em 1772, foi instituído a fim de garantir a manutenção do ensino primário e médio. Este subsídio, sob responsabilidade das câmaras, era obtido por meio de impostos que incidiam sobre a carne verde, o vinho, o vinagre e a aguardente. $\mathrm{O}$ valor reduzido do montante e a inconstância com que os professores eram remunerados pelos seus serviços contribuíram para agravar a situação que se intensificava, pois os professores eram mal preparados para o exercício da função, principalmente na colônia brasileira.

No âmbito do ensino jurídico, as transformações foram marcantes, revelando o embate e a relação do Estado com a Igreja. O predomínio da concepção do Direito Romano e Canônico passou a ser alvo de ques- tionamento na medida em que não atendia as novas questões, como o papel do Estado e a questão da nacionalidade. Neste sentido, podemos perceber que Pombal é guiado pelo movimento ideológico de uma cultura iluminista, tendo a obra de Luís António Verney como referência. É conveniente ressaltar que a ideia norteadora do processo de reforma era que a educação poderia estar a serviço da recuperação econômica. Neste sentido, deve ser compreendido o projeto de ênfase nas ciências naturais, especialmente mineralogia e botânica, que tinha como meta criar novas formas de exploração dos recursos naturais nas terras coloniais. ${ }^{37}$

Pelas novas diretrizes da Universidade de Coimbra, os estudantes de Filosofia Natural deveriam ter feito previamente um Curso de Humanidades. No que tange ao Curso de Filosofia Natural, a matéria de História Natural deveria abranger discussões sobre Zoologia, Botânica, Mineralogia e o conhecimento sobre a obra de Plínio, o Velho, que ocorria no segundo ano letivo. Estas disciplinas deveriam ser cursadas juntamente com Geometria, que era ministrada na Faculdade de Matemática. $\mathrm{O}$ aluno deveria se submeter aos exames, $\mathrm{e}$ somente se aprovado seguiria para o ano subsequente, pois dela dependia o estudo da Física Experimental. ${ }^{38}$

O estatuto determinava que a Filosofia fosse dividida em três grandes partes: a Racional, a Moral e a Natural, as quais seriam contempladas no curso da Universidade. A Filosofia Racional, compreendia a Lógica, elemento essencial para as operações de entendimento. Este ramo estudaria ainda: a Ontologia, que preparava para os primeiros princípios das ciências; a Pneumatologia, que compreendia a ciência dos espíritos, e se dividia em Teologia Natural, e Psicologia; e a partir delas a Metafísica, que tratava dos primeiros Princípios, e da Natureza Espiritual. A Filosofia Moral inerente à Ética e à Filosofia Natural abrangia todos os ramos da ciência que tivessem por objeto "a contemplação da Natureza, excetuando somente o que pertence em particular aos Cursos Médico, e Matemático; o primeiro dos quais se limita à Física do Corpo humano; e o segundo á Filosofia da Quantidade, enquanto suscetível de numero e de medida". ${ }^{39}$ Desta forma, o documento delineava a área de conhecimento que abrangia a Filosofia Natural. 
O Estatuto, tendo como referência os debates e as práticas de outras instituições europeias, entendia que:

não havendo outros meios de chegar ao conhecimentodaNaturezasenãoaObservação, e a Experiência; começará o "Curso de Fysica pela História Natural", em que se ensinam as verdades de facto pertencentes aos três Reinos da Natureza, havidas pela Observação o Sendo porém a Observação limitada aos factos, os Fenômenos, que a mesma Natureza offerece aos olhos dos homens no Curso ordinário das suas Operações; depois das verdades conhecidas pela Observação, será necessário passar ás que somente se podem haver por meio da Experiência; a qual obriga a mesma Natureza a declarar as verdades mais escondidas, que por si mesma não quer manifestar, senão sendo perguntada com muita destreza, e artifício. ${ }^{40}$

O documento tratava com destaque a parte experimental da Filosofia Natural, que deveria ter concebida a partir da Filosofia Experimental e da Filosofia Química. A Filosofia Experimental serviria para indagar as leis e as propriedades gerais dos corpos considerando-os como "móveis, graves, resistentes, \&c. e descobrir a razão dos factos conhecidos tanto pela Observação, como pela Experiência”. A Filosofia Química deveria questionar as propriedades particulares dos corpos, analisando os princípios e os elementos de que eram compostos. A meta era descobrir os efeitos e as propriedades de cada um e os resultados da mistura deles. ${ }^{41}$

$\mathrm{O}$ estatuto não se restringia às diretrizes principais do novo projeto. Ele era minucioso no detalhamento das disciplinas e dos conteúdos que cada uma delas. O documento revelava um projeto pedagógico preocupado com a maneira como as matérias seriam ministradas, mas também atento a como elas se inter-relacionavam. O papel do professor era importante em todo o processo, lembrando que estes deveriam funcionar como estímulo para o aluno. O docente deveria apresentar os conceitos e os fatos, somente depois fazer um trabalho sobre especulação do entendimento humano, de forma que o conteúdo ficasse devidamente esclarecido para o aprendiz. Este por sua vez, não deveria assistir às aulas de forma passiva, principalmente quando se tratava de aulas nos laboratórios. Era importante que participasse, fazendo experiências, e pela prática construísse hábitos e sagacidade, deixando de ser mero expectador da natureza. ${ }^{42}$

Como podemos observar, o curso foi concebido de forma que o aluno fosse agregando conhecimento em cada uma das etapas, o que era fundamental para a boa consecução da fase seguinte. O estatuto salientava a importância de orientar os discípulos à observação, por meio da prática, em seguida se daria ênfase ao conhecimento da matemática e, no momento adequado, deveriam ser acrescentados os estudos da Física Experimental e posteriormente o de Química. Nota-se que a ênfase na prática era uma constante, apesar de nem sempre existirem condições propícias para a realização de experiências. O mesmo documento revelava a importância desse conjunto de conhecimentos para os interesses da coroa portuguesa e benefício de todos os seres humanos.

As medições de lugares e terrenos, as táticas de campanha e da marinha, as construções da arquitetura naval, civil e militar, bem como as fábricas seriam beneficiadas por este saber. $\mathrm{O}$ conhecimento das terras coloniais atendia ao desejo de estabelecer uma territorialidade da posse, reconhecendo e demarcando os limites das possessões pertencentes a Portugal.

Conforme o estatuto, o conhecimento da natureza implicava deter habilidades para a cartografia e o desenho topográfico, bem como para o desenho de animais, plantas e minerais. Aqueles que desejassem realizar um curso superior, na Universidade de Coimbra, tinham que ter idade mínima de dezoito anos e saberem ler e escrever em latim, assim como ter conhecimentos suficientes de grego. $\mathrm{O}$ domínio do inglês e do francês era também importante. Para o curso de Medicina, havia um período preparatório e o estudante deveria possuir sólidos conhecimentos de História Natural, Lógica, Moral, Química, Física Experimental, Matemática, dentre outras disciplinas. Em seguida, havia um período de estudos mais aprofundados em diversas áreas durante cinco anos. O estudo da natureza era fundamental na 
formação do futuro médico, na medida em que teria que conhecer as propriedades das espécies da flora e da fauna para os tratamentos medicinais.

Nos laboratórios de estudo da natureza havia painéis com diversas espécies de folhas, sementes, cascas, raízes, animais que poderiam ser utilizados também pelos médicos. Além da identificação das espécies, os estudantes deveriam aviar a receita e preparar os medicamentos. Este conjunto de conhecimentos era ampliado pelas visitas ao jardim botânico, onde era possível identificar as espécies no mundo natural. Também eram importantes as pesquisas no âmbito da Anatomia, cujo objetivo era conhecer a estrutura do corpo humano e também dos animais. $\mathrm{O}$ uso de cadáveres humanos passou a ser comum, bem como a prática de dissecação das aves, a fim de se fazerem estudos comparativos que pudessem auxiliar na formação acadêmica. Estes elementos são importantes por evidenciar que o estudo da natureza, antes de conquistar uma relativa autonomia e definição no âmbito da História Natural, estava diretamente ligado aos estudos de Medicina.

A reformulação da Universidade de Coimbra não atingiu os cursos da mesma forma. Os Cursos das Ciências Naturais, que reuniam os cursos de Medicina, Filosofia e Matemática (que abarcavam a História Natural, a Química e a Física Experimental) foram os mais afetados. Nesta área os progressos foram expressivos.

Nesse movimento de transformações o ensino da arquitetura militar e civil sofreriam algumas alterações. No Estatuto da Universidade de Coimbra, no livro III, título VII, segunda parte, referente ao curso matemático, era tratado de todos os assuntos concernentes à criação, insígnias e privilégios da Matemática. Nestes itens eram apresentados em detalhes os elementos do Curso Matemático, como tempo, disciplinas, cadeiras e férias; distribuição das lições; exercícios, exames, atos e graus; estabelecimentos pertencentes à Matemática. ${ }^{43}$

Conforme Estatuto "as matemáticas" tinham "uma perfeição tão indisputável entre todos os conhecimentos naturais, assim na exatidão luminosa do seu Método, como na sublime, e admirável especulação das suas Doutrinas, que Elas não somente em rigor, ou com propriedade merecem o nome de Ciências". Pelo documento era estabelecida a "profissão Matemática" na Universidade de Coimbra em Corpo de Faculdade. Entendia-se que o ensino de Matemática tinha um fim importante que era o da manutenção e o ensino público das Ciências.

Tal situação revela a importância da Matemática naquele momento, sendo destacado a sua contribuição para o bem público e do reino. Defendia-se que Portugal tivesse "Matemáticos insignes, de cujas ideias se utilizem os Povos, e que possam ser proveitosamente empregados no meu Real serviço". O conhecimento matemático era fundamental para outros conhecimentos correlatos, pois elas auxiliavam na contagem do tempo, na localização geográfica dos lugares, nas demarcações, e medições dos terrenos, nas manobras de pilotagem naval, nas operações táticas realizas pela exercito e marinha, bem como na construção da Arquitetura Naval, Civil, e Militar.

O Curso de Matemática durava quatro anos, sendo composto pelas cadeiras de Geometria, Álgebra e Astronomia, mais as cadeira de Desenho e Arquitetura. Conforme a nova estrutura proposta haveria mais "extraordinariamente uma Cadeira de Desenho, e Arquitetura, tanto Civil, como Militar”. Ressaltava que estas não pertenceriam à ordem "das outras Cadeiras; por não haver nestas Artes aquela exatidão Matemática, que tem as Ciências acima referidas; constando em grande parte de Regras arbitrárias; e governando-se mais pelo gosto, do que por demonstração". ${ }^{44}$

A disciplina de arquitetura era uma cadeira constituída como as demais, sendo possível que um mesmo professor fosse responsável pelos cursos de civil e militar. O plano de ensino deveria seguir um conteúdo básico, por temática. Primeiramente era ministrado o conteúdo de arquitetura civil, cabendo ao professor mostrar os diferentes modos de edificar dos Antigos e dos Modernos; discorrendo sobre os meios, que deveriam ser aplicados para a segurança, comodidade, e decoração dos edifícios. O docente era responsável também por ensinar as diferentes ordens de arquitetura, e as obras que em cada uma delas teve lugar. Era importante formar nos discentes o "bom gosto", instigando-os a conseguirem os exemplos mais perfeitos, que até aquele momento conhecessem. Para tanto, os discípu- 
los deveriam ser estimulados a copiarem e desenharem ao mesmo tempo em que aprendiam os elementos necessários do desenho e do gosto na arquitetura.

$\mathrm{Na}$ etapa seguinte era desenvolvido o conteúdo da arquitetura militar. Neste momento deveriam ser explicados os fundamentos desta área, mostrando os "diferentes métodos de Fortificação, que se tem imaginado, tanto nas obras regulares, como nas irregulares: Sendo tudo acompanhado com o Desenho dos modelos mais perfeitos, que até o presente se tem executado".

$\mathrm{Na}$ etapa final, os alunos deveriam se dedicar a prática do "risco das Cartas Geográficas, e Topográficas". Além disso, era necessário exercitar o "Desenho dos animais, plantas, aves, e outros produtos da natureza, sem iluminação, e com iluminação". O objetivo destes exercícios era torná-los "hábeis a exprimir com exatidão, e primor qualquer objeto, que se lhes apresente, segundo forem ajudados do gênio, e da delicadeza manual, que esta Arte requer".

Aqueles que participassem desses cursos não eram obrigados a exame e recebiam no final dos estudos, quando pedissem, um certificado ou atestado, por despacho do Reitor, com o seu aproveitamento. Caso desejassem requer exame, a fim de obter "Carta de Aprovação", o discente deveria se apresentar perante um comitê de avaliação composto por quatro Lentes de Matemática. O candidato, na ocasião, deveria apresentar as provas de Desenho, que havia submetido outrora à aprovação do professor que ministrara a disciplina. $\mathrm{O}$ comitê avaliaria o conjunto dos trabalhos e faria as perguntas que julgasse necessária sobre a perspectiva e a arquitetura. Caso o aluno fosse aprovado pelos avaliadores, seria solicitada a emissão da "Carta de Aprovação".

É possível notar que os cursos eram compostos por matérias elementares e aquelas que subsidiavam a forma específica que deveriam desenvolver no seu bojo o conhecimento teórico e o pensamento analítico. Procurava-se articular com mais clareza o conhecimento teórico com o conhecimento prático, a partir do pensamento científico. Isto significava que o aluno deveria ser instado a ter uma postura que privilegiasse a exatidão e a ordenação dos elementos para realizar uma ponderação analítica mais adequada, ou seja, racionalização dos processos.
Desta maneira, pretendia-se que a Universidade de Coimbra passasse a oferecer à sociedade "saberes úteis" que poderiam servir ao bem de todos e guindar Portugal a uma posição de destaque, na medida em que poderia contribuir para o aumento da riqueza e do poder da nação. Este desejo esbarrou em problemas internos da nação portuguesa, eivado de contradições.

Portugal, aos olhos da Europa, era um país obscuro, estagnado em muitos segmentos, incapaz de atrair um olhar demorado das demais nações. E a fatalidade do dia primeiro de novembro de 1755 lançava-o no cenário da comoção mundial. Contudo, o ímpeto progressista de Sebastião José de Carvalho e Melo resultou o avanço e a reconstrução. ${ }^{45}$ Ao designar membros da burguesia para funções públicas burocratas, , ele priorizou a atividade comercial, tentando romper com as estruturas semifeudais.

A expulsão dos jesuítas e o atropelo das ações da monarquia portuguesa evidenciaram a falta de organização e a debilidade do projeto de uma política publica de ensino. Revelavam também uma grande firmeza e ousadia no projeto concebido por Sebastião José de Carvalho e Melo, apesar da dificuldade que enfrentou. Conforme destacou Maria Elizabete Xavier, a Reforma Pombalina representou a "reação da Coroa portuguesa à lenta agonia por que passava a sociedade lusitana, em processo de decadência, empobrecimento e perda da própria soberania". ${ }^{46}$

$\mathrm{O}$ projeto e grande parte da estratégia reformuladora não agradava a todos os setores da sociedade, mas somente àqueles que se achavam mais próximos do Primeiro-Ministro. Como bem observou Kenneth Maxwell, ao analisar a atuação de Sebastião José de Carvalho e Melo, o momento era o da consolidação de uma burguesia comercial, apoiada por ele, gerando:

reações dentro de Portugal precisamente porque interceptava outros conflitos no seio da sociedade portuguesa: entre a velha nobreza e homens de negócios novos-ricos; entre os modernizadores do sistema educacional e os defensores da tradição; e entre pequenos e grandes empresários. Pombal tratou a oposição implacavelmente. Suas reformas e seu despotismo eram, portanto, inseparáveis. ${ }^{47}$ 
Para solidificar o seu projeto de reforma a única via era o despotismo, em face das rebeldias e desvios presentes na sociedade portuguesa e colonial.

O objetivo de Pombal era criar uma instrução popular para a colônia, que não vingou, pois a escassez de professores e a fragilidade interna da colônia favoreceram a fragmentação do sistema educacional. E a proposta educacional da monarquia não contava com os quesitos necessárias para preencher o hiato deixado pelo modelo jesuíta. Com a ascensão de D. Maria I e o afastamento de Sebastião José de Carvalho e Melo da sua função, os projetos foram atalhados e ruíram. Contudo, nem a falta de condições para a manutenção dos professores ou os custos elevados para a manutenção das escolas, bem como outros problemas já salientados anteriormente nesta reflexão, anularam completamente as suas ações. Como ressaltamos, o projeto para a educação era um dos planos desenvolvidos para a colônia que se compunha com outros. No que tange à defesa do território da América Portuguesa, ao estímulo à imigração, à concessão de liberdade aos índios e à difusão da língua portuguesa, os resultados foram significativos e abalaram as estruturas coloniais.

Sebastião Jose de Carvalho e Melo teve como meta corrigir as defasagens das ações e opções dos monarcas anteriores. Este processo de transformação não foi implementado na sua totalidade em face de uma conjuntura de crise econômica que envolvia o reino. Contudo, o Primeiro-Ministro soube responder às necessidades do reino e de uma política que estimulava a produção e a capacidade produtiva das terras brasileiras. Projetos e ideias que já haviam sido cogitados, mas não foram postos em prática. Acreditou que eles poderiam ser de fundamental importância para reabilitar o reino e diminuir o grau de dependência que Portugal mantinha em relação a outras nações.

Apesar de em curto prazo os procedimentos interventores de Pombal terem abalado o sistema econômico, político e educacional da metrópole e da colônia, eles permitiram a ruptura do modelo antigo e a emergência de um novo modelo. O impacto histórico das suas determinações pode ser considerado como um verdadeiro terremoto que abalou o sonolento Estado português. Os estudiosos, cada um a seu modo, tentam reduzir ou aumentar a atuação da mão-de-ferro de Sebastião José de Carvalho e Melo, simplificando ou ressaltando as suas atitudes mais enérgicas como elementos negativos da sua atuação como Primeiro-Ministro. O fato é que esta gerou controvérsias na medida em que rompia com os objetivos de alguns segmentos da elite metropolitana e colonial. Para esta a intensa atuação do Primeiro-Ministro foi dramática, similar ao espetáculo de horror causado pela condenação e execução dos Távoras.

Modernizar a sociedade portuguesa era um grande empreendimento, radical na sua essência, cujo processo foi conduzido por um forte agente Os empecilhos não eram poucos, mas a qualidade de Sebastião de Carvalho Melo emergiam de seu virtuosismo e vanguardismo, apesar dos excessos que envolvem a imagem mítica do político. O fato é que ele, como Primeiro-Ministro, foi um dos homens responsáveis pelas transformações e mudanças, como observou José Eduardo Franco:

Sendo certo que a Sebastião José se deveu o protagonismo determinante da consecução da política Josefina, quer nos seus êxitos, quer nos fracassos, e dos projectos reformistas implementados então no reino, não é menos verdade que a condução desta política foi feita com total proteção e confirmação do Rei que, além do mais, lhe delegou poderes extraordinários para agir, poderes nunca até então cedidos a um ministro na história política da monarquia portuguesa. ${ }^{48}$

Suas deliberações envolvidas por uma aura iluminista, de fato não conseguiram ser transformadoras no grau e na intensidade desejáveis. O terremoto de José Sebastião de Carvalho e Melo fez ruir as estruturas antigas, dando ensejo ao surgimento de um novo modelo na educação. Aos poucos Portugal se reergueu, alçando voo para uma nova fase. 


\section{REFERÊNCIAS}

ABBAGNANO, Nicola. Dicionário de Filosofia. São Paulo: Martins Fontes, 2000.

ALMAÇA, C. Bosquejo histórico da zoologia em Portugal. Lisboa: Museu Nacional de História Natural, 1993, e ALMAÇA, Carlos: “Os Portugueses no Brasil e a Zoologia Pré-Lineana” In: A Universidade e os Descobrimentos. Lisboa: INCM, 1993.

ALMEIDA, M. Lopes de. Documentos da Reforma Pombalina, por Ordem da Universidade, Coimbra, 1937, vol. I (1771-1782).

ANASTACIO, Vanda. Viver em Lisboa no Tempo do Marquês de Pombal: uma breve panorâmica. In: VALE, Teresa Leonor M. (org.) A cidade pombalina: história, urbanismo e arquitectura os 250 anos do Plano da Baixa - Actas das Jornadas. Lisboa: Câmara Municipal de Lisboa, 2008, p. 17-28.

ANDRADE, Antônio Alberto Banha de. "A Reforma Pombalina dos Estudos Menores em Portugal e no Brasil”, in: Revista de História, n. 112, vol. LVI, ano XXVIII, São Paulo: USP, out/dez de 1977.

ARAÚJO, Ana Cristina. O Marquês de Pombal e a Universidade. Coimbra: Imprensa da Universidade de Coimbra, 2000.

AZEVEDO, João Lúcio de. O Marquês de Pombal e a sua época. Rio de Janeiro/ Lisboa/ Porto: Annuario do Brasil/Seara Nova/ Renascença Portuguesa, 1922.

BANGERT, W. História da Companhia de Jesus. São Paulo: Loyola, 1985.

BERNARDINO, Teresa. Sociedade e Atitudes Mentais em Portugal (1777-1810). Lisboa: Imprensa Nacional/Casa da Moeda, s.d.

CAEIRO, José - História da Expulsão da Companhia de Jesus da Província de Portugal. Salvador: Salesiana, 1936.

CARVALHO, L.R. As Reformas Pombalinas da Instrução Pública. São Paulo: EDUSP/Saraiva, 1978.

CRUZ, Guilherme Braga da. Ensaios Universitários. Origem e Evolução da Universidade. Lisboa: Logos, 1964.

CRUZEIRO, Maria Eduarda. "A reforma pombalina na história da Universidade”. In: Análise Social, vol XXIV (100), 1988, (1o.), p. 187-197

CURTO, Diogo Ramada. Ritos e cerimónias da monarquia em Portugal (séculos XVI a XVIII). In: A Memória da Nação. Lisboa: Sá da Costa, 1981.

DOMINGUES, Mário. Marquês de Pombal - o homem e sua época. Lisboa: Prefácio, 2002.

FALCON, Francisco J.C. "As práticas do reformismo ilustrado pombalino no campo jurídico", in: Revista de História das Idéias, vol. 18, 1996, pp. 511-527.
FALCON, Francisco José C. A época pombalina. São Paulo: Ática, 1982.

FERNANDES, A. "História da botânica em Portugal até fins do séc. XIX”. In: História e desenvolvimento da ciência em Portugal. Lisboa, Academia das Ciências de Lisboa, 1987.

FRANCA, Leonel, S.J. O método pedagógico dos jesuítas. Rio de Janeiro: Agir, 1952.

FRANCO, José Edudardo. "Marquês de Pombal - precursor do empreendedorismo político contemporâneo”. In: JARDIM, Jacinto e FRANCO, José Eduardo (Coord.) Portugal empreendedor. Lisboa: INCM, 2013.

FRANCO, José Eduardo e RITA, Annabela. O mito do marquês de Pombal. Lisboa: Prefácio, 2004.

GALVEZ, Lucía. Guaraníes y Jesuítas. Buenos Aires: Sudamericana, 1995.

GAY, Peter. The Enlightenment: an interpretation. The Science of Freedom. NY/London: W.W. Norton \& Company, 1969, vol. 1.

HAZARD, Hazard. La crisis de la Consciencia Europea. Madrid: Ediciones Pegasos, s.d.

KRATZ, Guillermo. El Tratado hispano-portugués de limites de 1750 y sus consecuencias. Roma: Institutum Historicum, 1954.

LEITE, António. "A ideologia pombalina: Despotismo Esclarecido e Regalismo", in: Brotéria, v. 114, no. 5/6, maio-jun/1982, p. 497-498).

LEITE, Serafim. História da Companhia de Jesus no Brasil. Lisboa/Rio de Janeiro: Portugália/INL, 1938-1949, vol. VIII.

LEONARDO, António J.; MARTINS, Décio; e FIOLHAIS, Carlos. "O Instituto de Coimbra e a Ciência na Universidade de Coimbra”. In: FIOLHAIS, Carlos; SIMÕES, Carlota e MARTINS, Décio. História da Ciência na Universidade de Coimbra 1772-1933. Coimbra: Imprensa da Universidade de Coimbra, 2013, p. 209-230.

LEMOS, Maximiliano. Ribeiro Sanches. A sua vida e a sua obra. Porto: Eduardo Tavares Martins Editor, 1911.

MACEDO, Jorge Borges de, A situação econômica no tempo de Pombal, Lisboa: Gradiva, 1989.

MAGAlHÃES, José Calvet de. História do Pensamento Econômico em Portugal. Da Idade Média ao Mercantilismo. Coimbra: [s.n.], 1967.

DOMINGUES, Mário. Marquês de Pombal - o homem e sua época. Lisboa: Prefácio, 2002.

MAXWELL, Kenneth. Marquês de Pombal. Paradoxo do Iluminismo. Rio de Janeiro: Paz e Terra, 1996. 
MELO, Sebastião José de Carvalho e. Memórias Secretíssimas do Marquês de Pombal e outros Escritos. Publicações Europa-América, [s.l.] , [s.d.].

MURTEIRA, Helena. "O projecto pombalino para Lisboa: antecendentes e enquandramento teórico". In: VALE, Teresa Leonor M. (org.) A cidade pombalina: história, urbanismo e arquitectura - os 250 anos do Plano da Baixa - Actas das Jornadas. Lisboa: Câmara Municipal de Lisboa, 2008, p. 55-68.

NOVAIS, Fernando A. Estrutura e dinâmica do antigo sistema colonial. São Paulo: Hucitec, 1989.

PAIVA, José Maria de. Colonização e catequese: 1549-1600. São Paulo: Cortez, 1982.

POMBAL, Marquês / Junta de Providência Literária. Compênido histórico da Universidade de Coimbra. Lisboa: Campo das Letras, 2008.

PRIORE, Mary del. O Mal sobre a terra. Rio de Janeiro: Topbooks, 2003.

RIBEIRO, Marília de Azambuja. "Marquês de Pombal e o fim do projeto educacional jesuítico em Portugal e seu império (séculos XVI-XVIII)". In: Clio - Série Revista de Pesquisa Histórica, N. 27-2, 2009, p. 192-278.RUSSELL-WOOD. Um mundo em movimento. Lisboa: Difel, 2006.

SANCHES, Ribeiro. Compêndio Histórico do Estado da Universidade de Coimbra [...]. Lisboa: Régia Officina Typ., 1771

SANTOS, Maria Alcina R. Correia Afonso dos "A ação diplomática de Sebastião José de Carvalho e Melo na corte de Viena de Áustria (1744-1749)", in: Pombal Revisitado, op. cit., vol. 1, pp. 414-437.

SCHWARZ, Lilia M. A longa viagem da biblioteca do reis. São Paulo: Companhia das Letras, 2002.

SERRÃO, Joaquim Veríssimo. História de Portugal (1750-1807). Lisboa: Verbo, 1996, vol. VI.

TEIXEIRA, António Braz, A filosofia jurídica. In: CALAFATE, Pedro (coord.) História do Pensamento Filosófico Português. As Luzes. Lisboa: Caminho, 2001, vol. III.

TEIXEIRA, Ivan. Mecenato Pombalino e Poesia Neoclássica. São Paulo: Edusp, 1999.

VOVELLE, Michel. (dir.), O Homem do Iluminismo. (Trad.), Lisboa: Ed. Presença, 1997.

XAVIER, Maria Elizabete et alli. História da Educação - a escola no Brasil. São Paulo: FTD, 1994.

\section{DOCUMENTOS}

- Biblioteca Nacional de Portugal - Pontos Principais a que se reduzem os abusos, com que os religiosos da Companhia de JESUS tem usurpado os domínios da América Portuguesa, e Espanhola. cód. 1601 - p. 99-103.

- Ordenações Filipinas, Livro IV, título XV.

- Estatuto do Colégio Real de Nobres da Corte e Cidade de Lisboa. Lisboa: Oficina de Miguel Rodrigues, 1761.

- Estatutos da Universidade de Coimbra. Lisboa: Regia Officina Typografica, 1773.

\section{NOTAS}

1 Sobre o terremoto ver: PRIORE, Mary del. O Mal sobre a terra. Rio de Janeiro: Topbooks, 2003.

2 RUSSELL-WOOD. Um mundo em movimento. Lisboa: Difel, 2006, p. 109.

3 João Lúcio de Azevedo. O Marquês de Pombal e a sua época. Rio de Janeiro/ Lisboa/ Porto: Annuario do Brasil/Seara Nova/Renascença Portuguesa, 1922, p.99.

4 Sobre o assunto ver: SERRÃO, Joaquim Veríssimo. História de Portugal (1750-1807). Lisboa: Verbo, 1996, vol. VI, p. 38-42.

5 BANGERT, W. História da Companhia de Jesus. São Paulo: Loyola, 1985, p. 444-446.

6 Sobre o assunto, ver: AZEVEDO, J. Lúcio. O marquês de Pombal e a sua época. p. 234-57 e MAXWELL, Kennneth. Marquês de Pombal - paradoxo do iluminismo. Rio de Janeiro: Paz e Terra, 1996, p. 69-94.

7 SCHWARZ, Lilia Moritz. A longa viagem da biblioteca dos reis. São Paulo: Companhia das Letras, 2002, p. 96. Ver também: MAXWELL, Kenneth. Marquês de Pombal - paradoxo do ilumismo. Rio de Janeiro: Paz e Terra, 1996, p. 180.

8 SCHWARZ, Lilia M. A longa viagem da biblioteca do reis. São Paulo: Companhia das Letras, 2002, p. 97.

9 NOVAIS, Fernando A. Estrutura e dinâmica do antigo sistema colonial. São Paulo: Hucitec, 1989, p. 27.

10 FALCON, Francisco José C. A época pombalina. São Paulo: Ática, 1982, p. 372. Ver sobre o assunto também p. 213-482.

11 MACEDO, Jorge Borges de. A situação econômica no tempo de Pombal, Lisboa: Gradiva, 1989, p.141-184.

12 HAZARD, Hazard. La crisis de la Consciencia Europea. Madrid: Ediciones Pegasos, s.d.

13 ANASTACIO, Vanda. Viver em Lisboa no Tempo do Marquês de Pombal: uma breve panorâmica. In: VALE, Teresa Leonor M. (org.) A cidade pombalina: história, urbanismo e arquitectura - os 250 anos do Plano da Baixa - Actas das Jornadas. Lisboa: Câmara Municipal de Lisboa, 2008, p. 17-28.

14 TEIXEIRA, António Braz, A filosofia jurídica. In: CALAFATE, Pedro (coord.) História do Pensamento Filosófico Português. As Luzes. Lisboa: Caminho, 2001, vol. III, p. 65.

15 GAY, Peter. The Enlightenment: an interpretation. The Science of Freedom. NY/London: W.W. Norton \& Company, 1969, vol. 1, p. 26.

16 ABBAGNANO, Nicola. Dicionário de Filosofia. São Paulo: Martins Fontes, 2000, p. 534.

17 TEIXEIRA, António Braz. A filosofia jurídica. In: CALAFATE, Pedro (coord.) História do Pensamento Filosófico Português. As Luzes. Lisboa: Caminho, 2001, vol. III, p. 65.

18 Além do Verdadeiro Método de Estudar, foram importantes no mesmo sentido as Cartas sobre a Educação da 
Mocidade e o Método para Estudar a Medicina, de Antonio Ribeiro Sanches.

19 Ribeiro Sanches no Compêndio Histórico do Estado da Universidade de Coimbra no Tempo da Invasão dos Denominados Jesuitas e dos Estragos Feitos nas Ciências e nos Professores e Diretores que a Regem pelas Maquinações, e Publicações dos Novos Estatutos por eles Fabricados. Lisboa: Régia Officina Typ., 1771. Acusava também que o declínio do ensino português se devia aos jesuítas.

20 Sobre as reformas pombalinas e as estratégias adotadas por Pombal, ver a obra clássica de Francisco J. C. Falcon, A época pombalina, op. cit., p. 135 e em especial ALMEIDA, M. Lopes de. Documentos da Reforma Pombalina, por Ordem da Universidade, Coimbra, 1937 Vol. I (1771-1782).

21 FRANCO, José Eduardo. "Marquês de Pombal - precursor do empreendedorismo político contemporâneo". In: JARDIM, Jacinto e FRANCO, José Eduardo (Coord.) Portugal empreendedor. Lisboa: INCM, 20

22 RIBEIRO, Marília de Azambuja. "Marquês de Pombal e o fim do projeto educacional jesuítico em Portugal e seu império (séculos XVI-XVIII)". In: Clio - Série Revista de Pesquisa Histórica, N. 27-2, 2009, p. 192-278.

23 Algumas ordens religiosas, franciscanos, carmelitas e beneditinos abriram escolas de primeiras letras a fim de preencher o vazio deixado pela educação jesuítica. Esta estrutura deficitária contribui somente para amenizar o impacto causado pela reformulação da educação.

24 MAXWELL, Kennneth. Marquês de Pombal - paradoxo do iluminismo. Rio de Janeiro: Paz e Terra, 1996, p. 128.

25 As povoações eram: Santo Ângelo, São Borja, São João, São Lourenço, São Luís, São Miguel e São Nicolau.

26 KRATZ, Guillermo. El Tratado hispano-portugués de limites de 1750 y sus consecuencias. Roma: Institutum Historicum, 1954, p. 27-8.

27 Sobre o assunto consultar GALVEZ, Lucía. Guaranies y Jesuitas. Buenos Aires: Sudamericana, 1995, p. 359-65.

28 No contexto colonial, podemos identificar a existência de leis que tratam da liberdade dos índios que datam dos anos de 1570, 1587, 1595, $1609,1611,1647,1655,1680,1755$ (sendo que esta última confirmava as anteriores no seu preâmbulo).

29 Pontos Principais a que se reduzem os abusos, com que os religiosos da Companhia de JESUS tem usurpado os dominios da America Portugueza, e Hespanhola. BNL - cód. 1601 - p. 99-103.

30 Ibidem, p. 102.

31 Sobre o assunto ver Ordenações Filipinas, Livro IV, título XV.

32 SERRÃO, Joaquim Veríssimo. História de Portugal (1750-1807). Lisboa: Verbo, 1996, vol. VI, p. 48.

33 Estatuto do Colégio Real de Nobres da Corte e Cidade de Lisboa. Lisboa: Oficina de Miguel Rodrigues, 1761.

34 Estatutos da Universidade de Coimbra. Lisboa: Regia Officina Typografica, 1773.

35 CRUZ, Guilherme Braga da. Ensaios Universitários. Origem e Evolução da Universidade. Lisboa: Logos, 1964, p. 52.

36 CRUZEIRO, Maria Eduarda. "A reforma pombalina na história da Universidade”. In: Análise Social, vol XXIV (100), 1988, (1o.), p. 187.

37 LEONARDO, António J.; MARTINS, Décio; e FIOLHAIS, Carlos. "O Instituto de Coimbra e a Ciência na Universidade de Coimbra”. In: FIOLHAIS, Carlos; SIMÕES, Carlota e MARTINS, Décio. História da Ciência na Universidade de Coimbra 1772-1933. Coimbra: Imprensa da Universidade de Coimbra, 2013, p. 209-230.
38 Sobre Zoologia ver: ALMAÇA, C. Bosquejo histórico da zoologia em Portugal. Lisboa: Museu Nacional de História Natural, 1993, e ALMAÇA, Carlos: "Os Portugueses no Brasil e a Zoologia Pré-Lineana” In: A Universidade e os Descobrimentos. Lisboa: INCM, 1993. Sobre Botânica ver: FERNANDES, A. "História da botânica em Portugal até fins do séc. XIX". In: História e desenvolvimento da ciência em Portugal. Lisboa, Academia das Ciências de Lisboa, 1987.

39 "Estatutos da Universidade de Coimbra de 1772" In: Compêndio histórico do Estado da Universidade de Coimbra no tempo da invasão dos denominados jesuítas, etc. De 1772. Liv. III, Pt. III, Tit. I, cap. II, 1-6.

40 Ibidem, Liv. III, Pt. III, Tit. I, cap. II, 1-6.

41 Ibidem, Liv. III, Pt. III, Tit. I, cap. II, 1-6.

42 Ibidem, Liv. III, Pt. III, Tit. I, cap. II, 2-4.

43 Ibidem, Liv. III, Pt. III, Tit. VII, Segunda Parte Do curso Matemático, título I a VIII, p. 141 a 221.

44 Ibidem Liv. III, Segunda Parte, Título III, Capítulo III, 6, p. 166.

45 MURTEIRA, Helena. "O projecto pombalino para Lisboa: antecedentes e enquadramento teórico". In: VALE, Teresa Leonor M. (org.) A cidade pombalina: história, urbanismo e arquitectura - os 250 anos do Plano da Baixa - Actas das Jornadas. Lisboa: Câmara Municipal de Lisboa, 2008, p. 55-68.

46 XAVIER, Maria Elizabete et alli. História da Educação - a escola no Brasil. São Paulo: FTD, 1994, p. 49.

47 MAXWELL, Kennneth. Marquês de Pombal - paradoxo do iluminismo. Rio de Janeiro: Paz e Terra, 1996, p. 170.

48 FRANCO, José Eduardo e RITA, Annabela. O mito do marquês de Pombal. Lisboa: Prefácio, 2004, p. 28.

\section{O AUTOR}

Paulo Assunção é Professor da Universidade Estadual de Paraná / Faculdade de São Bento - São Paulo. E-mail: assuncao@prestonet.com.br 